\title{
A review on the occasion of the retirement of Professor Philip Wood
}

\author{
E G L Bywaters
}

In 1956 the Empire Rheumatism Council, as it was then named, founded the Field Unit for Rheumatism Research (ERU). The first director was John Lawrence, followed in 1968 by Philip Wood, and, now, with Professor Wood's retirement in 1989 Alan Silman of the London Hospital has succeeded to this important post. It is thus an excellent time to review the ERU's swift rise to fame in the national and international rheumatism field and beyond, and its further potential for development in a rapidly changing world. Wood's citation from Heraclitus, that 'you never step twice into the same river', was a memorable reminder of today's problems, when the river flows faster than it has ever done before and when its flora and fauna are deteriorating even more rapidly owing to pollution in various forms.

The original impetus for these now famous studies came from the request of the Miners' Welfare Commission in 1948 to the departments of rheumatism (Professor Kellgren) and occupational health (Professor R E Lane) of the University of Manchester to survey rheumatism in miners. Dr John Lawrence was appointed to do this. He had had an unusual background: qualifying in 1930 in Edinburgh, he spent the next 18 years in junior hospital posts and general practice with occasional periods in research, and with the encouragement of Professor Francis Fraser at the Postgraduate Medical School of London at Hammersmith in 1938 he conducted a trial of the effects of gold on rheumatoid arthritis controlled by placebo injection, long before such precautions had become mandatory. From there he began research on the erythrocyte sedimentation rate, publishing a book on this subject, and thence to service in the Royal Air Force. He was led into the study of epidemiology through the National Coal Board in 1948 .

Rheumatic complaints were common $(30 \%)$ in both miners and non-mining employees of the National Coal Board, but loss of work, due largely to back and knee trouble, was significantly greater in the miners, associated with heavy lifting and stooping in low coal seams. Professor Kellgren in 1954 with a grant from the Medical Research Council extended these surveys, and in 1956 the Arthritis and Rheumatism Council set up the Field Unit with Dr Lawrence as director. Thenceforth population studies were started in numerous other areas as well as family studies in Manchester, Taplow, and Hammersmith, twin studies, and occupational studies, all with the aid of serological and radiological investigation and in close collaboration with other centres. The mobile equipment was supplied by the Wellcome Trust.

These surveys made a wide impact when published because for the first time we were made aware of the considerable prevalence of rheuma- toid arthritis and other rheumatic disorders in samples of the general population in Yorkshire and Wales, in the United Kingdom, and in other countries. This stimulated worldwide comparisons of this and other epidemiological aspects, culminating in the symposia on 'The Epidemiology of Chronic Rheumatism', the first being held in 1957 at the National Institutes of Health, Bethesda, Maryland, United States. The second was held in 1961 in Rome, the third in 1966 in New York, and the fourth in 1981 again in Bethesda. Epidemiology of chronic rheumatism was now a worldwide specialty interest.

In 1968 John Lawrence retired (although he has never stopped working relentlessly in the field up to this day) and the Arthritis and Rheumatism Council (ARC) appointed Philip Wood to succeed him. His 20 years in its service have brought new insights and most valuable returns through a more sophisticated and up to date approach, including the study of new and different aspects of epidemiology.

Philip Wood, with clinical and research experience in Sheffield, St Bartholomew's Hospital in London, the Royal Postgraduate School in Hammersmith and Buffalo, New York, entered the field of epidemiology and rheumatism in 1965 at Manchester on an ARC fellowship and quickly began to make his mark by questioning and defining those classic concepts used in classification and statistical studies. The Unit under his direction has since played a most important part in the national and international field in establishing the scientific basis of epidemiological terminology.

'Biography is about chaps; Geography is about maps'

wrote E Clerihew Bentley. We might add

'The epidemiologist

Takes both for his grist'.

Epidemiology is about both, but the maps are now of many dimensions. The 'chaps' are not individually named, as in clinical medicine, but statistically batched or boxed and classified according to age, sex, and numerous other attributes, depending on sample size and computer capability.

The way we now use the word 'epidemiology' has changed considerably from its former use: 'the study of epidemics of disease in man'. Firstly, it has been enlarged to include a more general study of diseases in man other than epidemic infections: their prevalence, distribution, and development over time with particular regard to any possible genetic or environmental causes. Secondly, it has been extended to include the distribution and prevalence of populations of plants, insects, and even perhaps coat hangers, which, it has been of London

Present address:

Longacre, 53 Burkes

Road, Beaconsfield,

Buckinghamshire

E G L Bywaters 


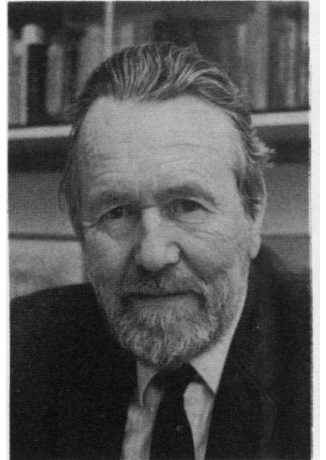

Professor Philip Wood predicted, may succeed human beings as the dominant species by the end of the next century.

Philip Wood proceeded from the classic epidemiological studies of the early years of the Unit to a follow up study of a Welsh population and a study of gout in the Cotswolds in the United Kingdom. By the early 1970s, however, it became apparent that without further basic scientific discoveries the study of epidemiology of the chronic rheumatic diseases was up against a brick wall with no apparent way forward if classical methods continued to be used. The discovery of Lyme disease could be accommodated within the traditional framework and was quietly dispatched by Steere and Malawista. This was an easy victory though compared with the challenge of the chronic arthritides, backache, soft tissue rheumatism, or many of the other 200 odd rheumatic diseases which are recognised today. The discovery of the haplotype HLA-B27 in 1973 opened the way for the bricks to be painstakingly taken down and examined. In the meantime epidemiology seemed to be at a dead end and waiting for new signposts and directions.

From 1968 Philip Wood nevertheless leapfrogged all the older limitations implied by the definition of epidemiology in his response to the needs of the age, and indeed also to the increasingly sparse returns of the 'older epidemiology' in the field of rheumatic disease.

The 'seventies and 'eighties saw rising expectations and diminishing returns: an increasing proportion of older people, an increased differential between the prosperous South and the old industrial North in the United Kingdom (to which Manchester belonged) and, latterly, a new distribution of wealth between the rich and the poor, which imposed new difficulties. There was also a deficit of maintenance of the infrastructure of the country on which all long term prosperity depends: this was the background of the 'new epidemiology'.

The major contributions of the Unit's new policy were to centre on the increased demand for rheumatological services brought about by better treatment methods and by the changing demographic profile of the population. There are now many more elderly people and fewer school leavers to recruit into the National Health Service. The service has suffered from long waiting lists, staff shortages, and capital cuts, not helped by reduction in public spending by the government in the universities, and there is, in addition, a rising inflation rate, which has recently reached $8 \cdot 3 \%$.

Internationally, when 1977 was designated 'World Rheumatism Year', British rheumatology sustained by the ARC responded admirably, highlighting this cumulative problem of resources versus needs. The Arthritis and Rheumatism Council issued more than seven publications, emanating largely from the Field Unit, dealing with different aspects of patient needs and their supply.

These publications included The Challenge: Problems and Progress in Health Care for Rheumatic Disorders and other reports on the availability or otherwise of specialist rheumatologists and the provision of orthopaedic surgery within and between the various regions of the United Kingdom. Other publications dealt with services potentially available for rheumatism sufferers but lacking in certain areas, such as welfare facilities and social support. 'A publication, The Price We
Pay, dealt with the impact of the rheumatic diseases on the individual and the community. Finally, there was a seminal report on Undergraduate Education in Rheumatology.

These surveys were meticulously researched and clearly written in plain language, each covering a wide field, and they led to important actions then, which are still relevant today. The problem of the adequate care of these chronic and increasingly common diseases is still unsolved; its solution depends upon the future policy basis for the NHS.

Before, during, and after these vivid portrayals of our urgent national problem-that is, the gap between the needs of the large number of sufferers from chronic rheumatism and the personnel and resources available to deal with them-Philip Wood has kept up intensive efforts in national and international communication in this field. Foremost perhaps amongst these was his work with the World Health Organisation (WHO). He played a major part in updating the 9th revision of the WHO International Classification of Diseases (ICD). This was followed by collaboration with a group including William Feltz of the United States on the development of the ICD (Rheumatic and Orthopaedic) undertaken under the auspices of the International League against Rheumatism.

One of his major contributions will be seen to be the International Classification of Impairments, Disabilities, and Handicaps (ICIDH), which was published by WHO for trial purposes in 1980. An important part of this report is the model of the consequences of disease, which underpins the classification. The model suggests a sequence of consequences arising from a disease or disorder. Firstly, impairments and defects in structure or functioning of the body may result. These may then give rise to disabilities, restrictions, or inabilities in the performance of activities. In turn these may then lead to handicap and limit or prevent the fulfilment of normal social roles, depending on age, sex, and social and cultural factors. These differences between frequently confused categories are important for health, social, and legal workers, and, indeed, politicians. The ideas of the ICIDH are gradually being taken up throughout the world, and are giving a new impetus and perspective, particularly to those concerned with rehabilitation and the care of disabled people in the community.

The work of the Unit under the direction of Philip Wood has laid a firm basis for future research, basic and applied, into the rheumatic and related diseases of the locomotor system. The assessments of the state of care in the United Kingdom for rheumatic patients, together with the reviews of resource and manpower statistics which were initiated under Professor Philip Wood and Dr Elizabeth Badley and their highly professional team, remain a major source of facts and figures for professional and social action in the rheumatism field. It is to be hoped that such assessments will be continued in the ARC Epidemiology Research Unit under its new director Alan Silman. His new programme will undoubtedly address new problems. It will, we can be sure, maintain the Unit's high profile and continue to add significantly to our knowledge of these common and various rheumatic diseases; their causation, prevention, amelioration, and perhaps even, who knows, cure.

My thanks are due to Professor Kellgren, Dr John Lawrence, and Dr Elizabeth Badley for their help in the making of this contribution. 